\title{
An Analysis of Interlanguage Features and English Learning
}

\author{
Xin Wang ${ }^{1}$, Lingling Fan ${ }^{2 *}$ \\ ${ }^{1}$ Dean's Office, Haiyuan College of Kunming Medical University, Kunming 650500, China \\ ${ }^{2}$ English teaching and Research Office, Yunnan University Secondary School, Kunming 650091, China \\ Email: fan.11@msn.com
}

\begin{abstract}
The term interlanguage was first used by American linguist, Larry Selinker ${ }^{[2]}$. It is the unique linguistic system because it is neither L1 nor L2 but at the same time bears resemblances to both, which functions as a relatively systematic transition from initial knowledge of a language tonative proficiency during the process of language acquisition, and is always regarded as an unstable set of language characteristics produced by learners. Fossilization in interlanguage is significant in English learning. It is a universal phenomenon in Second Language Acquisition and it derives from multiple factors. This paper analyzes the conception and the causes of the phenomenon. Through this research, we should hold a totally different view from traditional one on the nature and function of teacher's training, teaching materials and the handling of the learners' errors, etc. It tries to propose some solutions to deal with fossilization so as to improve the effect gains in English learning.
\end{abstract}

Keywords: interlanguage, target language, fossilization, language learning

\section{Introduction}

As for English learners and potential English teachers, we can find that after they reach the certain stage of development, they cannot achieve L2 proficiency further in the process of learning and teaching. Selinker noted that many L2 learners ( perhaps as many as 95 percent ) failed to reach target language competence. The phenomenon mentioned above lead us to consider the reason why majority of the L2 learners stop progressing in their acquisition of the target language. In fact, as L2 learners, we learn English at an environment where English is a target language. In essence, this language is a transition language. Interlanguage is closed to target language. But influenced by native language, learner's learning motivation, learning strategy, cognitive methods, psychology, and language level and language environment, there is some difference between interlanguage and target language. Interlanguage becomes a new study field in linguistics in recent years. Interlanguage theory and its fossilization phenomenon play an important role in English language learning and teaching.

\section{Literature review}

\subsection{The definition of interlanguage and its fossilization phenomenon}

Interlanguage is the concept in the theory of Second Language Acquisition, which was promoted by American linguist Selinker in Cambridge International Forum. In 1972, Selinker discussed this term more comprehensively in a paper named Interlanguage ${ }^{[1]}$. He pointed out that interlanguage is the separateness of a second language learner's system, a system that has a structurally-intermediate status between the native and target language. ${ }^{[2]}$ In a word, interlanguage is a language system between native language and target language and used by L2 learners. This system is different from learners' native language and target language in the aspect of phonetics, vocabulary, grammar, culture and communication function. And it is a motive language system approaching to correct target language in the process of study and progress. This system starts with native language and approaches to target language gradually, but it is not equal to target language. Then, what is interlanguage fossilization? There are two level meanings for fossilization. One is that, in general, interlanguage cannot reach the same level of target language forever. The other is that some learners cannot make any progress when they reach a certain state. From theory aspect, interlanguage can reach the final place ( the target language ) along with deepening study and increasing volume of study. But, in the practice aspect, the fact is far from than that.

\subsection{The features of fossilization phenomenon}

The interlanguage system of Second Language or Foreign Language learners has some principle features in common, which they share with other simplified systems such as mother talk, foreigner talk, and pidgin. ${ }^{[3]}$

\subsubsection{Interlanguage is dynamic}


To begin with, the L2 or FL learner's interlanguage is dynamic. Compared with some other forms of language growth, interlanguage are typically changing rather fast in development terms as leaners receive more input and revise their hypotheses about $\mathrm{L} 2$.

\subsubsection{Interlanguage is permeable}

The L2 learner's interlanguage system is permeable, in the sense that rules that constitute the learner's knowledge at any stage are not fixed, but open to amendment. In many respects it's a general feature of natural languages, which evolve over time in ways not dissimilar to the developments that take place in interlanguage. ${ }^{[4]}$

\subsubsection{Interlanguage is systematic}

Despite the variability of interlanguage, it is possible to detect the rule-based nature of the learner's use of the Second Language. He doesn't select haphazardly from his store of interlanguage rules, but in predictable ways. He bases his performance plans on his existing rule system in much the same way as the native speaker bases his plans on his internalized knowledge of the L1 system.

\subsubsection{Fossilization}

The concept of interlanguage might better be understood if it is thought of as a continuum between the First Language and Second Language along which all learners traverse. But it is worth nothing that many Second Language learners fail to reach full target language competence. In other words, they do not reach the end of the interlanguage continuum. Fossilization occurs in most language learners and cannot be remedied by further instruction. Fossilized structures may not be persistent, however. On occasions the learners may succeed in producing the correct target language form, but when the learners is focused on meaning - especially if the subject matter is difficult - he will 'backslide' towards his true interlanguage norm. For some reason, they are unable to reactivate the "latent language structure". ${ }^{[5,6]}$

Then, I would like to emphasize the following facts about fossilization:

-it can be conscious,

-it is not experienced as a problem by individuals,

-it is deeply connected to the idea of purpose,

-it is changeable, i.e. it can be modified if purposes and factors vary,

-it is difficult to eradicate,

-and finally, it is unpredictable. ${ }^{[7]}$

Selinker noted that many L2 learners ( perhaps as many as 95 percent ) failed to reach target language competence. They stop learning when their interlanguage contains at least some rules different from those of the target language system. An important characteristics that can be observed in the study of the interlanguage of the second and foreign language learners is the fact that some language features that are part of the learners' interlanguage and differ from the correct or more adequate target language form do not seem to follow any kind of progression towards proficiency in the target language but quit the opposite. ${ }^{[8]}$ These interlanguage forms seem to be used by language learners in spite of their theoretical capacity to get the correct target language forms.

The phenomenon mentioned above lead us to consider the reason why majority of the L2 learners stop progressing in their acquisition of the target language and why some kinds of errors tend to persist in their interlanguage. Though the reach into interlanguage and its fossilization, we should hold totally different view from traditional one the nature and function of teaching materials and the handling of learners' errors, etc.

\section{Methods of studying interlanguage}

\subsection{Comparison method}

Selinker has promoted that there should be three comparable resources of linguistic dates. Firstly, learners ( nonnative speakers ) communicate though target language, which is Lernersprache ( LS for abbreviation ). Secondly, learners communicate though mother language, which is Muttersprache ( MS for abbreviation ). Thirdly, native speakers communicate though their mother language, which is Zielsprache ( ZS for abbreviation ). These linguistic dates are very important for linguistic study. LS data as learners' language system is the essential object that is studied. Because interlanguage in Applied Linguistics studies learners' language.

MS data and ZS data are the reference dates when we analysis learners' language. Researchers can study whether there is the trace of mother language transference though comparing MS data and LS data. And ZS data can be regarded as the standard of usage of target language for language learners. According to ZS data, researchers can find some specialties and shortages of language learners'. ${ }^{[9]}$ 
In order to make these three linguistic dates comparable, treaties should be in the same linguistic tasks and language context when they communicate. At later $20^{\text {th }}$ Century, in order to improve the Chinese students' English communicating ability, some linguistic researchers began to study taking Letting communicating ability become realizable study target as object. Though horizontally comparing among native speakers' English, Chinese learners' English and Chinese learners' Chinese, some implementation differences and similarities can be found. In this way, feasible program can be produced for improving students' communicating ability. This kind of research has been introduced in America and Europe. Interlanguage researchers find some interlanguage's specialties and shortages so as to provide important teaching contents though comparing the speech act implementation's similarities and differences among collected target language data, interlanguage speech data and mother language data. Taking this as fundament, people deign to explore the more feasible teaching methods. And they explore students' linguistic applied acquisition ability and development features, regulations and influence, or some possible factors to further development of applied linguistic ability. But up to now, there is small linguistic field concerning this object.

As those mentioned above, in comparison method, target language data is taken as target language usage standard. So it is necessary to discuss the problem of language using. That is, whether linguistic features in collected target language data can be the standard of target language using standard, and can be the goal to SL or FL learners. Kasper believe that both communicators should be corresponding to each other rather than approach to target language standard completely. There are three reasons. Firstly, there is a tremendous difference between target language culture and the specialties of native speakers' language usage. Therefore, it is hard to define which specialty is the real standard. Secondly, as is proved, the comments from native speakers for non-native speakers' different expressing ways in target language communicating process are not all bad. On the contrary, they feel interesting about that. Thirdly, it is impossible and unwilling for non-native speakers to close to target language using standard in target language communicating process. Therefore, in the interlanguage study, we should not only analysis learners' language learning shortages and problems, but also focus on learner' some interesting features possibly appearing in communicating process or some successful periods in communication. The production of these interesting features may be made by learners though utilizing some communicative strategies, or both communicators are negotiating, or they try to be corresponding to each other. Hence, they are worth collecting and introducing.

\subsection{Theory annotation, testing, comprehending method}

Theory Annotation Method refers to theoretically think about learners' language using ability acquisition and its development in cognition field. While, Testing Method aims at different foreign language teaching methods to make experimental study about the influence produced though learners' language using ability acquisition and development. Its detail operational approach is that explizit teaching method is carried out in one class, and implizit teaching method for another class. Then, we compare these two class's language using teaching effects.

It is difficult to make objective valuation to these study dates. So Comprehending Method should be carried out in language study process. In another word, in most situations besides those methods mentioned above, we also can do some class observations, reviewing and rethinking interview, questionnaire survey and collecting learners' learning dairies and so on so as to ensure or improve study's validation and reliability.

\section{Analysis reasons of interlanguage fossilization phenomenon}

\subsection{Cognitive psychology and psycholinguistics are the psychological bases of interlanguage}

From this perspective, Second Language Acquisition or Foreign Language Learning is a process of accumulating, reorganizing and creating.

There are three formation models of interlanguage: 1) drawing on mother tongue. L2 learners trend to apply the models or rules to the learning of the target language. 2) expanding the modes of the target language. L2 learners often use a word or a drill pattern by analogy without considering the discrepancy of culture, background, thinking, morality, and the like between the two nations. 3) expressing oneself with learned words and grammar. This is called communication strategy beginners use to make up of their lacking in grammar, words, and expressions.

\subsection{There are many of the cognitive process responsible for SLA. slinker suggested the five principle processes operated in interlanguage}

\subsubsection{Language transference}

In the process of Second Language Learning, learners may use rules in native language to deal with target language consciously or subconsciously, because they don't get the whole target language rules. This phenomenon mentioned 
above is native language transference. And when there are some similarities among characteristics from native language and target language or these similarities are the same, the transference can be called positive transference. In contrast, when there are some differences in those characteristics, we still use native language rules, which can be called negative transference. For instance, learners' pronunciation may be influenced by mother tongue and bears deep local accent, which is negative transference and has negative influence to SLA.

\subsubsection{Transference training}

Transference training is that teachers' unsuitable or non-native language using and unsuitable using of materials make learners misunderstand and misuse target language's rules. If these mistakes happen at primary stage, they may have rooted effects to subsequent study in the future.

\subsubsection{Study strategy for second language learning}

Learners utilize some special ways or methods to obtain and manage language input materials in study process. Some strategies are conductive, and this kind of fossilization can be corrected; some other strategies are psychological and logical, then this kind of fossilization is rooted and cannot be eliminated.

\subsubsection{Communication strategy of second language}

Quite a few language learners who communicate with native speakers realize that some errors don't hinder their expression of ideas, so they are misled to hold the opinion that it's unnecessary to further develop interlanguage so long as it doesn't affect communication. This situation can easily result in fossilization of interlanguage when learner receives active affective feedback. Another type of learners will form affective obstacle once they are criticized or negatively evaluated for their errors. Such a brief evaluation will easily extinguish the learner's confidence, malting them give up and from the fossilization of some wrong pronunciations.

After bearing a certain language ability, in order to communicate learners may use avoidance, simplification, appealing to the authority, prefabricated pattern and language shit and so on.

\subsubsection{Overgeneralization of target language}

Overgeneralization means that learners misuse a grammar rule or a word that have learned before to other language context.

Based on the analysis above, we can conclude that interlanguage fossilization do not inherent, it forms gradually in the process of study. Interlanguage, in form aspect, can be divided into two: individual fossilization and social fossilization. In nature aspect, it can be divided into internal fossilization and temporary fossilization. Concerning language teaching for English major in university, many students' language fossilization phenomenon belongs to temporarily individual fossilization phenomenon. It can be remitted or weakened though both teachers' and students' efforts.

\section{Remission fossilization to improve learning efficiency}

Fossilization does not inherent. It forms in long study process. There are many reasons leading to fossilization. If teachers and learners can pay attention to these reasons, fossilization can be remitted and improve study efficiency and also optimize study effect.

\subsection{Positive attitudes towards errors}

"Error" is a grammatically incorrect form, and in linguistics, it generally refers to the learner's misuse or misunderstanding of the target language, grammatically or pragmatically. ${ }^{[10]}$

Some teachers never or seldom correct students' errors, as a result of which students cannot sense the errors which they have made so that the proportion of error repetition is very high. Furthermore, if some students' errors have not been corrected for a long time, it is possible that their errors will be considered as the correct input by other students. In this regard, teachers may repeat the meanings students express in the right form to correct students' errors skillfully; for the serious errors made in written work, teachers should point them out immediately.

It is believed, with the effort that teachers and students make, that students can be spared the pain of severe language anxiety and can experience what it means to succeed in the language classroom.

\subsection{Strengthen positive-interference and shorten negative-interference}

Language positive-inference mainly embodies in contents and forms, especially, in cultural background knowledge and common sense. For English teaching at university, teachers should make use of language positive-interference. And experience generalized from studying native language can be used to promote English language learning. Language negative-interference mainly embodies in pronunciation, application and grammar. For example, after long time English learning, many learners still remains Chinese pronunciation because they are influenced by local dialect. In this situation, 
teachers should encourage students to speak more, listen more and imitate more, and encourage them to correct the mistakes of pronunciation consciously. In the aspect of grammar, there are some similarities and differences between English grammar and Chinese grammar. After all, English and Chinese belong to two different language families. When we study English, we may make multifarious and countless errors on grammar. For example, students may make the sentence like this: She is nurse. This kind of sentence is affected by native language. There are no articles in Chinese. Sometimes, when students translate the sentence“他们玩得很开心 ”, they may say They played very happily. This situation belongs to using word without consideration. "Play" in English means play cards, play a ball game and play music. “玩的开心 ” idiomatic expression is have a good time. What's more, in word order aspect, there is big unlikeness between English and Chinese. Therefore, Chinese students may easily make errors on word order. So, teachers should provide correct guidance. Generally speaking, when learners' interlanguage is at primary stage, learners may rely on the pattern of native language to think and express. Therefore, negative-interference of native language is stranger than others. As English level being promoted, learners are dependent on native language gradually. Errors made by negative-interference of native language may be reduced.

By comparing the learners' native language with the target language, differences could be identified and used to predict areas of potential error. In this way classroom practice could be directed on the problem areas in order to help the learner overcome the negative effects of first language transfer.

\subsection{Input and output should be balanced in class}

From the discussion above, we can conclude that both comprehension input and output play an important role both in English learning and interlanguage development and that teachers should not ignore either of them but try to make good use of both of them. In English teaching, therefore, teachers may join students' groups in talking, create an interactive and emotionally safe environment, and provide them with more authentic meaningful materials, encouraging them to participate in classroom activities more actively to get more opportunities for comprehensible input and output.

As teachers of English, we should place emphasis on the role of input. Likewise, the significance of learners' output should not be overlooked either. Learners need the opportunity for meaningful use of their linguistic resources to achieve full grammatical competence.

\subsection{Attaching importance to the quality of language input and output}

Language input premises language output; then language output is the final goal of input. In the process of output, learners' hypothesis on interlanguage are being proved or demolished. In this way, this non-individual body of interlanguage is approaching to target language, and obstacle to improve language ability is being weakened. In the practice of English study, the main reason leading to interlanguage fossilization is fake language input. In order to improve language input quality, teachers should improve language ability; on the other hand, the quality of teaching material also should be improved. Teaching materials should better use original materials. Reality not only embodies in reading comprehension training, but also in listening training, speaking and writing training and other skills' training. In general, when language learners reach an expertly level, adequately understandable language input should be provided for learners. What's more, the level of input information should be above than learners' interlanguage, and it should be repeated again and again to benefit students' study. If input content given from teachers is higher than present level, students will be afraid of that. Consequently, this psychology may block language expression. However, if the input information is too simple, students will lose interest of study. Countering these characteristics, teachers should not only pay attention to the degree of easy-hard, but also increase the delight of input information to let students keep the confidence and interest of study.

Language input is the comprehension process; while language output is internalized expression after comprehension. Teachers play the important role in students' language output that they make in class. Because of restriction and influence from different conditions and the language levels of learners of their own, learners hard to avoid to using native language thinking pattern to solve problems. At this time, output relies on native language seriously, and interlanguage is forming gradually. If teachers can give positively emotional feedback or negatively cognitive feedback, encouraging function can be produced, and at the same time, can make students adjust and correct their own language. In this way, interlanguage stays at the unstable state so that fossilization can be forbidden. Meanwhile, in order to help students to produce language output, teachers should organize students to carry out more and more colorful outside activities to extend and expend class education, which can provide learners with comfortable, real and natural context to foster their quality of communication, and in this way, their language ability can be improved.

\subsection{Optimize learning methods}

In a sense, the L2 of the teacher is still an interlanguage ( expect those teachers who are native speakers of the 
language ), which means his presentation differs from the target language. Even though students could grasp all the language information which teachers provide ( this is impossible), what they grasp is still an interlanguage.

Therefore, it is very important to teach and train learning strategies. Having the proper learning strategy means that students have the ability and method to analyze and organize any new information, and then they are able to evaluate their learning process and learning outcome appropriately.

In the process of Second Language Acquisition, learners are main parts and actively initiative participants. They may mobilize their knowledge and strategies which have learned before consciously or subconsciously when they try to complete study tasks or cognition tasks. Therefore, we should not only notice the efficiency of studying target language, but also should pay attention to the common strategies and skills in learning all sorts of languages. Besides, teachers also should keep their eyes on study strategy input rather than spoon-feed. They should help students set short term goal and long term goal of study. And they can encourage students to value their study progress in the certain long time. All of those mentioned above make students' passive study transfer to initiative study. Therefore, learners had better continually revise their own study style approaching to make effort to native language positive transference to benefit the cognitively psychological procedure.

\subsection{Improve teachers' proficiency and the quality of teaching material}

Teachers need not only to improve their proficiency in English but also to master some information of teaching methods. There are two roles of teachers: one is to explain lexical and grammatical knowledge for students; another is to provide learners with optimal input. Most teachers pay little attention to the second role, so they don't know what kind of method is efficient to introduce the material of target language.

The main problems of teaching materials in China are displayed in three aspects: obsolete language form and content, confusion between written and spoken language, and misuse of British English and American English in some aspects, such as the usage of definite articles and some certain prepositions. Learners will make such kind of errors that are difficult to eliminate when they don't notice these differences. This is what Selinker calls the fossilization caused by training transfer. In addition, teaching materials must be authentic. The so-called "authentic" refers to the fact that the selective materials must be actual conversations among native speakers or articles written by natives, but not those written for teaching a certain grammatical phenomenon or sentence patterns. Some teachers may think that all the original editions of textbooks are actual language input, but it is not the case. Some original editions of textbooks are written only for learners to grasp some certain sentence patterns, ignoring authenticity.

\section{Conclusion}

Created by L2/ FL learners, interlanguage is a unique and dynamic linguistic system. The interlanguage will be of some help, especially in the early stages. It is comprehensible in many cases.

All in all, the study of interlanguage and its fossilization plays the crucial role in Second Language Acquisition and foreign language teaching and learning. Teachers should keep in mind that interlanguage is a process which is approaching the target language step by step. Learning some related linguistic knowledge is good for improving teachers' theoretical levels. During this process students slowly revise the interim systems to accommodate new hypotheses about the target language system. This kind of study can help teachers to formulate suitable teaching plans and teaching aims according to language learning principles and students' different language levels, which can guide students to learn more effectively and put off or reduce interlanguage fossilization in order to approach to the final target. 


\section{References}

[1] Selinker, L. Language Transfer. General Linguistics. 1969; 9: 67-92.

[2] Selinker, L. Interlanguage. IRAL. 1972; 10: 3.

[3] Nemser, W. Approximative System of Foreign Language Learners. IRAL. 1971; 2: 115-123.

[4] Rod Ellis. Understanding Second Language Acquisition. London: Oxford University Publishing; 1985. p.107-231.

[5] Lenneberg E. Biological Foundation of Language. New York: Wiley; 1967.

[6] Ellis, Rod. The Study of Second Language Acquisition. Oxford University Publishing; 1994.

[7] Adjemain, C. On the nature of interlanguage systems. Language Learning. 1976; 26: 297-320.

[8] Ellis, R. Understanding Second Language Acquisition. Shanghai: Shanghai Foreign Language Teaching Publishing; 1999.

[9] Selinker, L. Rediscovering Interlanguage. White Plains: Longman Publishing; 1992.

[10] Corder, S. The Significance of learners' errors. International Review of Applied Linguistics. 1967; 5: 61-70. 